\title{
Diffuse Alveolar Hemorrhage Emerging One Week after Starting High-dose Corticosteroid Therapy for Granulomatosis with Polyangiitis (GPA) with Systemic Lupus Erythematosus (SLE)
}

\author{
Shoichi Fukui ${ }^{1}$, Naoki Iwamoto ${ }^{1}$, Sosuke Tsuji ${ }^{1}$, Masataka Umeda ${ }^{1}$, Ayako Nishino ${ }^{1}$, \\ Yoshikazu Nakashima ${ }^{1}$, Takahisa Suzuki ${ }^{1}$, Yoshiro Horai ${ }^{1}$, Tomohiro Koga ${ }^{1}$, \\ Shin-ya Kawashiri ${ }^{1,2}$, Kunihiro Ichinose ${ }^{1}$, Yasuko Hirai ${ }^{1}$, Mami Tamai ${ }^{1}$, Hideki Nakamura ${ }^{1}$, \\ Tomoki Origuchi ${ }^{1,3}$ and Atsushi Kawakami ${ }^{1}$
}

\begin{abstract}
A 69-year-old man was diagnosed with granulomatosis with polyangiitis (GPA) based on the presence of skin granuloma, refractory otitis media, renal insufficiency and myeloperoxidase-antineutrophil cytoplasmic antibody positivity and slight lung opacity. He was treated with high-dose corticosteroid therapy. Despite the initial improvement of his renal function and a decrease in his C-reactive protein level, he suffered from an alveolar hemorrhage one week after the start of corticosteroid therapy. An anti-dsDNA antibody test was positive and the patient had hypocomplementemia. Elements of both GPA and systemic lupus erythematosus were thought to have affected his clinical course.
\end{abstract}

Key words: ANCA-associated vasculitis, diffuse alveolar hemorrhage, MDS, SLE

(Intern Med 54: 2681-2686, 2015)

(DOI: 10.2169/internalmedicine.54.5299)

\section{Introduction}

Antineutrophil cytoplasmic antibody (ANCA)-associated vasculitis (AAV) is characterized by vasculitis of the smallto medium-sized vessels; however, its etiology remains unknown. There are three types of AAV: eosinophilic granulomatosis with polyangiitis (EGPA), granulomatosis with polyangiitis (GPA), and microscopic polyangiitis (MPA). AAV often presents with pulmonary involvement. Diffuse alveolar hemorrhage (DAH) is a lung manifestation that is present in $10 \%$ of GPA cases (1). DAH shows a characteristic clinical and radiological pattern of acute hypoxemic respiratory failure with a diffuse ground glass appearance or consolidation of both lungs. It is often associated with kidney disease (2). DAH is associated with a poor prognosis. The one-year sur- vival rate of DAH associated with AAV is only 50\% (3). DAH is related to the disease activity of AAV, including other organ involvement, and often occurs as the initial manifestation of AAV before the initiation of treatment. On the other hand, DAH also occurs in patients with systemic lupus erythematosus (SLE) (4). We present a characteristic case of GPA with SLE associated with DAH in which the onset of symptoms occurred after the improvement of the patient's systemic condition, which included renal insufficiency, in response to corticosteroid therapy.

\section{Case Report}

A 69-year-old man was admitted to our hospital with a fever of two weeks duration. The antibiotics prescribed by another physician after the onset of his fever were ineffec-

\footnotetext{
${ }^{1}$ Department of Immunology and Rheumatology, Nagasaki University Graduate School of Biomedical Sciences, Japan, ${ }^{2}$ Department of Public Health, Nagasaki University Graduate School of Biomedical Sciences, Japan and ${ }^{3}$ Department of Rehabilitation Sciences, Nagasaki University Graduate School of Biomedical Sciences, Japan

Received for publication March 8, 2015; Accepted for publication May 18, 2015

Correspondence to Dr. Shoichi Fukui, fukui-ngs@umin.ac.jp
} 
tive. The patient's appetite declined and skin eruptions appeared on his face and neck. His medical history was unremarkable. He had a 45-year history of smoking 20 cigarettes a day (between 20 and 65 years of age).

On physical examination, the patient's body temperature was $38.0^{\circ} \mathrm{C}$. His face and neck showed fused scaled erythematous papules (Fig. 1), and he had oral ulcers. Auscultation of the chest revealed fine crackles over the back lower lung field. There was no edema in either leg. His right tympanic membrane was perforated. There were no signs or symptoms of nasal involvement. The laboratory data were as follows: white blood cell (WBC) count $(2,700 / \mu \mathrm{L})$, hemoglobin $(10.4 \mathrm{~g} / \mathrm{dL})$, platelet count $(9.3 / \mu \mathrm{L})$, C-reactive protein $(\mathrm{CRP})(2.4 \mathrm{mg} / \mathrm{dL})$, serum creatinine $(\mathrm{Cr})(1.9 \mathrm{mg} / \mathrm{dL})$, rheumatoid factor $(13 \mathrm{IU} / \mathrm{mL}$; normal range: $<15 \mathrm{IU} / \mathrm{mL})$,

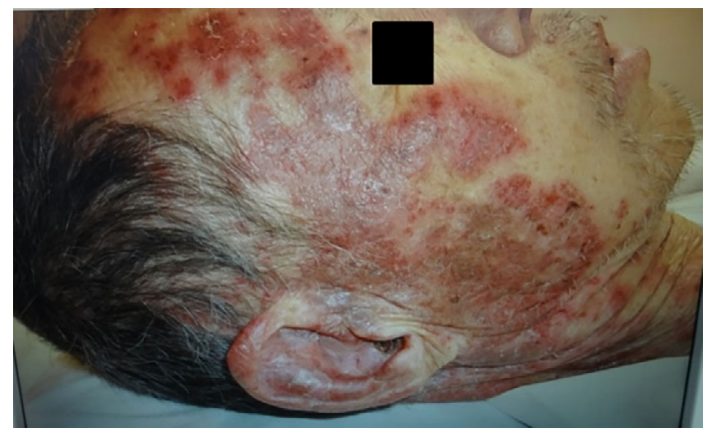

Figure 1. Fused scaled erythematous papules on the patient's face and neck. anti-double-stranded DNA antibody (anti-dsDNA antibody) (13.4 IU/mL; normal range: $<12 \mathrm{IU} / \mathrm{mL})$, sialylated carbohydrate antigen (KL-6) (321 U/mL; normal range: <500 U/ $\mathrm{mL})$, surfactant protein A (SPA) $(70.8 \mathrm{ng} / \mathrm{mL}$; normal range: $<43.8 \mathrm{ng} / \mathrm{mL}$ ). The patient had a high myeloperoxidaseantineutrophil cytoplasmic antibody (MPO-ANCA) level of 83.4 enzyme-linked immunosorbent assay (ELISA) units $(\mathrm{EU}) / \mathrm{mL}$ (normal range: $<12 \mathrm{EU} / \mathrm{mL}$ ). A test for proteinase 3 (PR3)-ANCA was negative. A urinalysis revealed microscopic hematuria (10-20 red blood cells/high-power field), proteinuria $(2.2 \mathrm{~g} / \mathrm{g} \mathrm{Cr})$ and granular casts (Table 1). Chest CT showed minimal thickening of the pleura (Fig. 2a), honeycombing, consolidation, and interstitial reticular markings (Fig. 2b).

A skin biopsy specimen analysis revealed leukocytoclastic vasculitis with granulomas. We performed a bone marrow puncture because the patient had pancytopenia. His bone marrow specimen showed prominent hypocellular bone marrow. The patient's poor condition and the decline in his platelet count precluded a renal biopsy.

The patient was diagnosed with GPA based on the Chapel Hill Consensus Conference (CHCC) criteria (5) and the European Medicines Agency (EMA) algorithm with exploratory surrogate markers for GPA (6), due to his high MPOANCA level, and the presence of leukocytoclastic vasculitis with skin granulomas and otitis media of the right ear, and renal insufficiency with red blood cells and granular casts in urine. The patient's oral ulcers, renal disorder, positivity for anti-dsDNA and antinuclear antibodies and his low comple-

Table 1. Laboratory Test Results upon Admission.

\begin{tabular}{|c|c|c|c|c|c|c|c|}
\hline & Norm & Result & Unit & & Norm & Result & Unit \\
\hline WBC & $3,500-9,100$ & 2,700 & $/ \mu \mathrm{L}$ & ANA & $<\times 40$ & $\times 320$ & $\begin{array}{l}\text { Homogenous } \\
\text { /Speckled }\end{array}$ \\
\hline Seg & $40-60$ & 75 & $\%$ & $\mathrm{RF}$ & $<15$ & 13 & $\mathrm{IU} / \mathrm{mL}$ \\
\hline Ly & $25-50$ & 15 & $\%$ & ACPA & $<4.5$ & $<4.5$ & $\mathrm{IU} / \mathrm{mL}$ \\
\hline Mo & $1-14$ & 9 & $\%$ & KL-6 & $<500$ & 321 & $\mathrm{U} / \mathrm{mL}$ \\
\hline Eo & $0-5$ & 1 & $\%$ & SPA & $<43.8$ & 70.8 & $\mathrm{ng} / \mathrm{mL}$ \\
\hline $\mathrm{RBC}$ & $3.76-5.00$ & 3.1 & $/ \mu \mathrm{L}$ & SPD & $<110$ & 289 & $\mathrm{ng} / \mathrm{mL}$ \\
\hline $\mathrm{Hb}$ & $11.3-15.2$ & 10.4 & $\mathrm{~g} / \mathrm{dL}$ & MPO-ANCA & $<3.5$ & 83.4 & $\mathrm{EU} / \mathrm{mL}$ \\
\hline PLT & $13.0-36.9$ & 9.3 & $/ \mu \mathrm{L}$ & PR3-ANCA & $<3.5$ & $<3.5$ & $\mathrm{EU} / \mathrm{mL}$ \\
\hline TP & $6.7-8.3$ & 5.5 & $\mathrm{~g} / \mathrm{dL}$ & $\begin{array}{l}\text { Anti-GBM } \\
\text { antibody }\end{array}$ & $<7$ & $<7$ & $\mathrm{U} / \mathrm{mL}$ \\
\hline ALB & $4.0-5.0$ & 1.4 & $\mathrm{~g} / \mathrm{dL}$ & $\begin{array}{l}\text { Anti-dsDNA } \\
\text { antibody }\end{array}$ & $<12$ & 13.4 & $\mathrm{IU} / \mathrm{mL}$ \\
\hline UN & $8-22$ & 28 & $\mathrm{mg} / \mathrm{dL}$ & PA-Ig & $<46$ & 249.8 & $\mathrm{ng} / 10^{7}$ cells \\
\hline $\mathrm{Cr}$ & $0.4-1.1$ & 1.9 & $\mathrm{mg} / \mathrm{dL}$ & Coombs test & & Negative & \\
\hline CRP & $<0.30$ & 2.38 & $\mathrm{mg} / \mathrm{dL}$ & & & & \\
\hline ESR & $2-10$ & 105 & $\mathrm{~mm} / \mathrm{hr}$ & Urine red cells & $0-5$ & $10-20$ & /HPF \\
\hline $\operatorname{IgG}$ & $870-1,700$ & 2,210 & $\mathrm{mg} / \mathrm{dL}$ & Granular casts & None & 2 & $/ \mathrm{LPF}$ \\
\hline $\mathrm{C} 3$ & $65-135$ & 44.4 & $\mathrm{mg} / \mathrm{dL}$ & Urine TP & $<0.5$ & 2.2 & $\mathrm{~g} / \mathrm{gCr}$ \\
\hline $\mathrm{C} 4$ & $13-35$ & 12.0 & $\mathrm{mg} / \mathrm{dL}$ & & & & \\
\hline CH50 & $30-45$ & 10.3 & $\mathrm{CH} 50 / \mathrm{mL}$ & & & & \\
\hline
\end{tabular}

WBC: white blood cell count, Seg: neutrophilic granulocyte segmented form, Ly: lymphocytes, Mo: monocytes, Eo: eosinophils, RBC: red blood cell count, Hb: hemoglobin, PLT: platelet count, TP: total protein, ALB: albumin, UN: nitrogen, Cr: creatinine, CRP: C-reactive protein, ESR: erythrocyte sedimentation rate, IgG: immunoglobulin G, CH50: complement activities, ANA: antinuclear antibodies, RF: rheumatoid factor, ACPA: anti-citrullinated peptide antibody, KL-6: sialylated carbohydrate antigen, SPA: surfactant protein A, SPD: surfactant protein D, MPO-ANCA: myeloperoxidase antineutrophil cytoplasmic antibody, PR3-ANCA: proteinase 3 antineutrophil cytoplasmic antibody, GBM: glomerular basement membrane, PA-Ig: platelet-associated immunoglobulin, HPF: high-power field, LPF: low-power field 


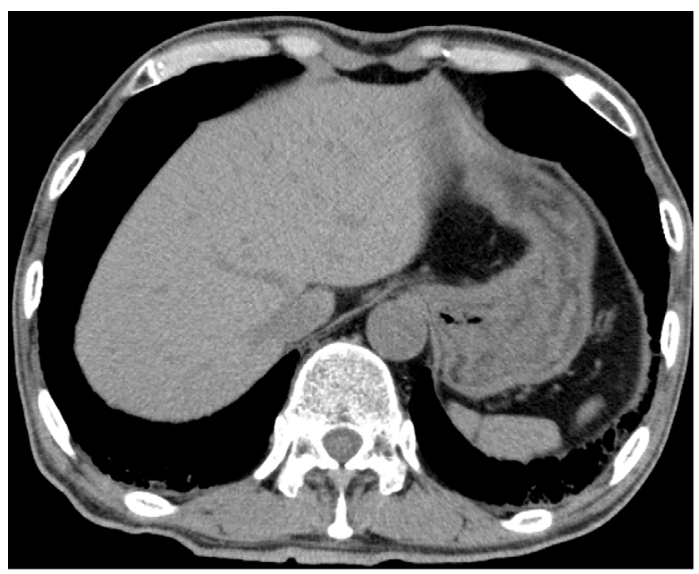

(a)

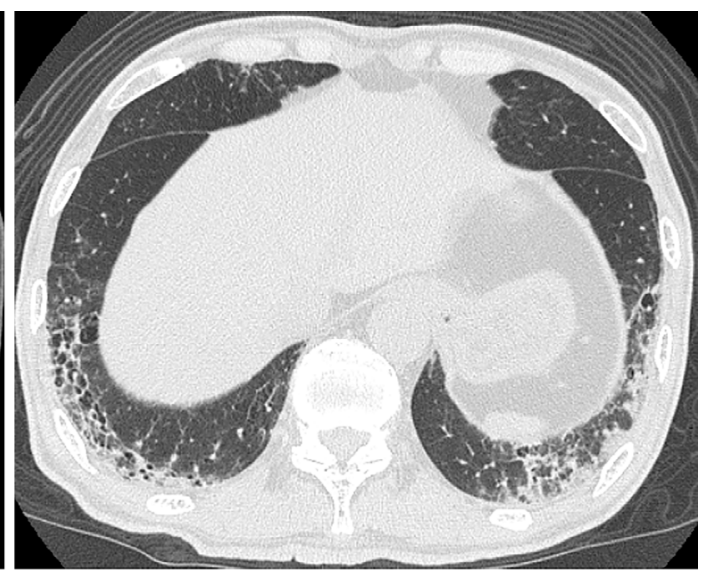

(b)

Figure 2. Minimal thickening of the pleura (a), honeycombing, consolidation, and interstitial reticular markings (b).

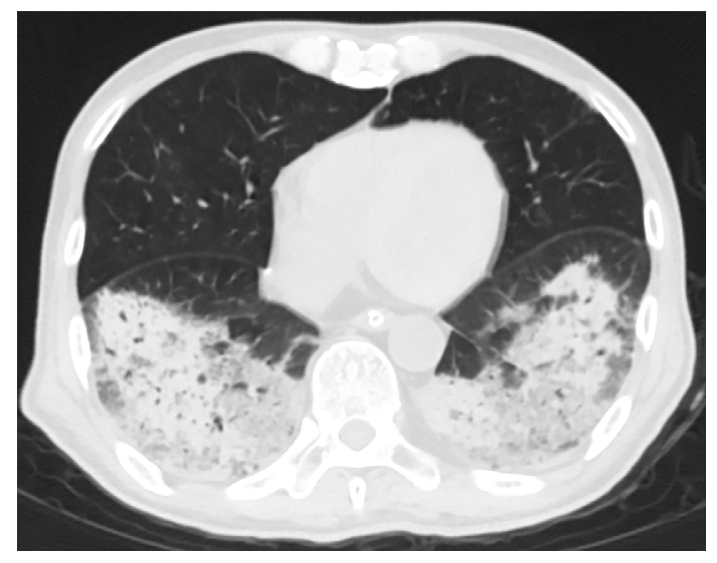

Figure 3. New bilateral diffuse consolidation in the lower lobes, one week after starting high-dose corticosteroid therapy.

ment levels also fulfilled the 1997 American College of Rheumatology (ACR) classification criteria (7), and the 2012 Systemic Lupus International Collaborating Clinics (SLICC) classification criteria (8) for SLE. The patient had also been diagnosed with myelodysplastic syndrome (45, XY, add (7) (p13), -11, del(20) (q12q13), Intermediate-2) by a hematologist.

Following treatment with pulsed methylprednisolone (PMPSL; 1,000 mg/day for 3 consecutive days per week), we started treatment with oral prednisolone $(50 \mathrm{mg} / \mathrm{day})$. The patient's fever declined, his skin eruptions and renal function improved, and his otitis media showed gradual improvement.

One week after starting therapy (MPO-ANCA titer: 28.9 $\mathrm{EU} / \mathrm{mL}$ ), the patient experienced chest pain and hemoptysis. Computed tomography (CT) showed new bilateral diffuse consolidation in his lower lobes. This finding and the concurrent progression of the patient's anemia were suggestive of DAH (Fig. 3). At the same time, his serum Cr level, microscopic hematuria and granular casts improved, but his hypocomplementemia worsened and his anti-dsDNA antibody titer increased (Table 2). There was no elevation in the serum levels of antibodies to adenovirus serotypes 3, 7, 21 (neutralization test) or Mycoplasma pneumonia (particle agglutination) in samples that were taken on days 1 and 18 . We hypothesized that the patient's DAH was complicated with GPA, despite the improvement of his other GPA symptoms, including renal insufficiency. However, the patient's hypocomplementemia and the increase in his anti-dsDNA antibody level suggested that his DAH was caused by SLE.

The patient was treated with P-MPSL for 3 weeks (3 consecutive days per week), and underwent three cycles of plasmapheresis (3 consecutive days per week) in our intensive care unit with intubation. Soon after treatment, his creatinine level increased and red blood cell casts appeared in his urine. We added intravenous cyclophosphamide pulse therapy (IVCY; $750 \mathrm{mg}$, once biweekly). His bilateral lung fields showed sufficient improvement to allow extubation. The patient's serum $\mathrm{Cr}$ level declined, the red blood cell casts in his urine disappeared, and his MPO-ANCA titer declined.

After the improvement of his alveolar hemorrhage, the patient became febrile again and a new consolidation emerged in the bilateral upper lung fields. A cytomegalovirus (CMV) antigenemia test [C7-horseradish peroxidase (HRP)] was positive (49 cells/50,000). We started treatment with ganciclovir and tazobactam/piperacillin (TAZ/PIPC) based on the empirical findings; however, the patient remained febrile and his C7-HRP level (42 cells/50,000) showed no decline after two weeks of TAZ/PIPC treatment. Ganciclovir was changed to foscarnet because we suspected ganciclovir-resistant CMV. In addition, we changed TAZ/ PIPC to trimethoprim/sulfamethoxazole based on the results of antimicrobial susceptibility testing after Stenotrophomonas maltophilia grew in a sputum culture. Under this new treatment, the consolidation of the bilateral upper lung fields improved, the Stenotrophomonas maltophilia in the sputum culture disappeared and a C7-HRP test became negative. During this period, we continued to administer IVCY (750 $\mathrm{mg}$, once biweekly) in accordance with the recommenda- 
Table 2. Laboratory Test Results at First DAH.

\begin{tabular}{|c|c|c|c|c|c|c|c|}
\hline & Norm & Result & Unit & & Norm & Result & Unit \\
\hline WBC & $3,500-9,100$ & 7,900 & $/ \mu \mathrm{L}$ & $\mathrm{C} 3$ & $65-135$ & 42.0 & $\mathrm{mg} / \mathrm{dL}$ \\
\hline $\mathrm{RBC}$ & $3.76-5.00$ & 2.0 & $/ \mu \mathrm{L}$ & $\mathrm{C} 4$ & $13-35$ & 10.0 & $\mathrm{mg} / \mathrm{dL}$ \\
\hline $\mathrm{Hb}$ & $11.3-15.2$ & 6.7 & $\mathrm{~g} / \mathrm{dL}$ & $\mathrm{CH} 50$ & $30-45$ & 18.5 & $\mathrm{CH} 50 / \mathrm{mL}$ \\
\hline PLT & $13.0-36.9$ & 11.4 & $/ \mu \mathrm{L}$ & MPO-ANCA & $<3.5$ & 28.9 & $\mathrm{EU} / \mathrm{mL}$ \\
\hline $\mathrm{TP}$ & $6.7-8.3$ & 4.6 & $\mathrm{~g} / \mathrm{dL}$ & $\begin{array}{l}\text { Anti-dsDNA } \\
\text { antibody }\end{array}$ & $<12$ & 24.2 & $\mathrm{IU} / \mathrm{mL}$ \\
\hline ALB & $4.0-5.0$ & 1.4 & $\mathrm{~g} / \mathrm{dL}$ & & & & \\
\hline UN & $8-22$ & 46 & $\mathrm{mg} / \mathrm{dL}$ & Urine red cells & $0-5$ & 0 & /HPF \\
\hline $\mathrm{Cr}$ & $0.4-1.1$ & 1.0 & $\mathrm{mg} / \mathrm{dL}$ & Granular casts & None & 0 & /LPF \\
\hline CRP & $<0.30$ & 0.12 & $\mathrm{mg} / \mathrm{dL}$ & Urine TP & $<0.5$ & 0.2 & $\mathrm{~g} / \mathrm{gCr}$ \\
\hline ESR & $2-10$ & 20 & $\mathrm{~mm} / \mathrm{hr}$ & & & & \\
\hline
\end{tabular}

Table 3. Laboratory Test Results at Second DAH.

\begin{tabular}{clrlclrl}
\hline & Norm & Result & Unit & & Norm & Result & Unit \\
\hline WBC & $3,500-9,100$ & 10,900 & $/ \mu \mathrm{L}$ & $\mathrm{C} 3$ & $65-135$ & 138.3 & $\mathrm{mg} / \mathrm{dL}$ \\
$\mathrm{RBC}$ & $3.76-5.00$ & 2.5 & $/ \mu \mathrm{L}$ & $\mathrm{C} 4$ & $13-35$ & 34.7 & $\mathrm{mg} / \mathrm{dL}$ \\
$\mathrm{Hb}$ & $11.3-15.2$ & 7.5 & $\mathrm{~g} / \mathrm{dL}$ & CH50 & $30-45$ & 53.7 & $\mathrm{CH} 50 / \mathrm{mL}$ \\
$\mathrm{PLT}$ & $13.0-36.9$ & 1.6 & $/ \mu \mathrm{L}$ & MPO-ANCA & $<3.5$ & $8.4 \mathrm{EU} / \mathrm{mL}$ \\
$\mathrm{TP}$ & $6.7-8.3$ & 5.4 & $\mathrm{~g} / \mathrm{dL}$ & Anti-dsDNA & $<12$ & $<12$ & $\mathrm{IU} / \mathrm{mL}$ \\
$\mathrm{ALB}$ & $4.0-5.0$ & 1.8 & $\mathrm{~g} / \mathrm{dL}$ & & & & \\
$\mathrm{UN}$ & $8-22$ & 33 & $\mathrm{mg} / \mathrm{dL}$ & Urine red cells & $0-5$ & $100<$ & $/ \mathrm{HPF}$ \\
$\mathrm{Cr}$ & $0.4-1.1$ & 0.67 & $\mathrm{mg} / \mathrm{dL}$ & Granular casts & None & 5 & $/ \mathrm{LPF}$ \\
$\mathrm{CRP}$ & $<0.30$ & 15.34 & $\mathrm{mg} / \mathrm{dL}$ & Urine TP & $<0.5$ & 26.2 & $\mathrm{~g} / \mathrm{gCr}$ \\
$\mathrm{ESR}$ & $2-10$ & 82 & $\mathrm{~mm} / \mathrm{hr}$ & & & & \\
\hline
\end{tabular}

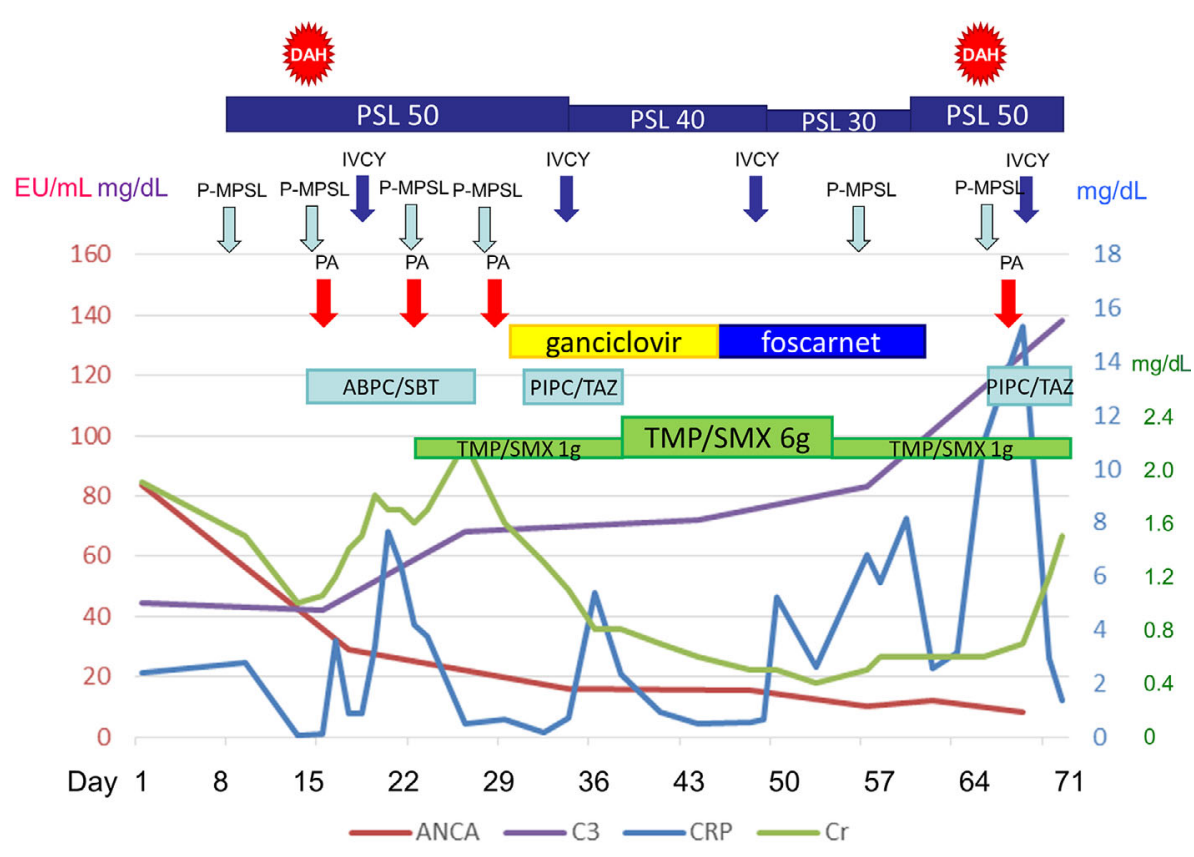

Figure 4. The clinical course of the 69-year-old male patient.

tions of the European Vasculitis Study (EUVAS) group.

However, one week later, his CRP level started to increase and the patient became febrile again. In contrast, to the previous laboratory findings, there was no increase in his MPO-ANCA titer. A 1,3-beta-D-glucan test and antigen tests for Aspergillus galactomannan, Candida albicans and Cryptococcus neoformans were negative. We suspected a relapse of vasculitis and administered P-MPSL. However, three days later, the patient suffered a second alveolar hemorrhage. Table 3 shows the laboratory test results. We reperformed plasmapheresis and resumed the administration IVCY $(750 \mathrm{mg})$. In spite of these treatments, the patient's alveolar hemorrhage and renal function consistently worsened, his Cr level increased, and he died of respiratory failure (Fig. 4). The patient's family requested that no autopsy was performed. 


\section{Discussion}

We herein discuss the case of a patient with GPA and SLE associated with DAH whose systemic condition, which included renal insufficiency, showed initial improvement in response to high-dose corticosteroid therapy. Hirayama et al. reported that the incidence of DAH in AAV is $15.4 \%$ in the Japanese population (9). In AAV with DAH, the incidence of AAV with ear, nose, throat (ENT) symptoms (which may suggest GPA) is reported to be $46.8 \%$. In most cases, DAH occurs as an initial manifestation of AAV. Kostianovsky et al. reported that 77 of $80(96.3 \%)$ AAV patients with DAH experienced hemoptysis as one of the initial manifestations of AAV (10). In another study of $53 \mathrm{AAV}$ patients with DAH, DAH occurred in 7 patients (13.2\%) as a manifestation of the relapse of AAV (11). In our patient, it is difficult to say whether DAH was an initial manifestation or if it indicated a relapse of AAV.

Our patient had a very unusual clinical course. DAH occurred despite the initial improvement of his systemic symptoms, which included renal insufficiency, after high-dose corticosteroid therapy. Moreover, his ANCA titer showed a gradual decline in response to the treatment. Although it remains unclear whether the ANCA titer reflects the disease activity of AAV, longitudinal ANCA measurements are reported to be a useful predictor of relapse in AAV patients with renal involvement (12). In our patient, the emergence of DAH was not parallel to the other activities or results associated with AAV, including the MPO-ANCA titer level.

Considering our patient's renal insufficiency at the time of the diagnosis, we should have started IVCY treatment as soon as possible. Earlier treatment might have prevented DAH. However, it was difficult to administer IVCY soon after the diagnosis of AAV because our patient had pancytopenia as a result of his myelodysplastic syndrome (MDS).

Our patient's condition was complicated by MDS. There have been some reports regarding MDS and ANCA positivity. Komatsuda et al. reported that MPO-ANCA-positive crescentic glomerulonephritis was associated with MDS in patients with trisomy 7 (13). Hull et al. reported a series of 12 patients with myelodysplasia of whom at least 4 showed a low peripheral ANCA titer, while and one showed a high peripheral ANCA titer. Two of these patients also showed demonstrable activity against myeloperoxidase (MPO); none of the patients showed any evidence of systemic or cutaneous vasculitis or of any autoimmune disorder (14). Hamidou et al. reported that, among 60 patients with MDS in their prospective study, only one had cytoplasmic ANCA-positive systemic vasculitis (15).

Based on these reports, we believe that our patient had both AAV and MDS independently. However, his low platelet count (which was the result of MDS) may have contributed to the severity of his DAH, and contributed to his death through the complication of hemorrhage.

Our patient also had hypocomplementemia and was posi- tive for anti-dsDNA antibody. His symptoms met both the 1997 ACR criteria (7) and the 2012 SLICC criteria (8) for SLE. Hervier et al. reported four cases of de novo SLE associated with AAV which fulfilled the criteria for both SLE and AAV (16). Our patient may be categorized into this group. At his initial presentation, he suffered from DAH without many of the elements of AAV, suggesting the possibility that his DAH was caused by SLE, not AAV. SantosOcampo et al. reported that the risk of developing DAH in SLE cannot be predicted based on the prior disease activity of SLE (17). This point may strengthen our hypothesis.

However, at the second episode of DAH, our patient's laboratory data did not show hypocomplementemia or an elevation of the level of anti-dsDNA antibodies. This suggested that, unlike the first episode, the second episode of DAH may have been caused by AAV, not SLE. Nevertheless, the etiology of our patient's DAH was unclear; however, it might have been affected by both AAV and SLE.

In conclusion, we experienced a case of GPA associated with DAH, which occurred after the patient's systemic condition, which included renal insufficiency, showed initial improvement in response to high-dose corticosteroid therapy. Elements of both AAV and SLE were thought to have affected the clinical course of our patient. It is useful to know that AAV with both hypocomplementemia and anti-dsDNA antibody positivity or SLE with ANCA positivity may have an unusual clinical course.

The authors state that they have no Conflict of Interest (COI).

\section{References}

1. Homma S, Suzuki A, Sato K. Pulmonary involvement in ANCAassociated vasculitis from the view of the pulmonologist. Clin Exp Nephrol 17: 667-671, 2013.

2. Niles JL, Bottinger EP, Saurina GR, et al. The syndrome of lung hemorrhage and nephritis is usually an ANCA-associated condition. Arch Intern Med 156: 440-445, 1996.

3. Gallagher H, Kwan JT, Jayne DR. Pulmonary renal syndrome: a 4-year, single-center experience. Am J Kidney Dis 39: 42-47, 2002.

4. Kamen DL, Strange C. Pulmonary manifestations of systemic lupus erythematosus. Clin Chest Med 31: 479-488, 2010.

5. Jennette JC, Falk RJ, Bacon PA, et al. 2012 revised International Chapel Hill Consensus Conference Nomenclature of Vasculitides. Arthritis Rheum 65: 1-11, 2013.

6. Watts R, Lane S, Hanslik T, et al. Development and validation of a consensus methodology for the classification of the ANCAassociated vasculitides and polyarteritis nodosa for epidemiological studies. Ann Rheum Dis 66: 222-227, 2007.

7. Hochberg MC. Updating the American College of Rheumatology revised criteria for the classification of systemic lupus erythematosus. Arthritis Rheum 40: 1725, 1997.

8. Petri M, Orbai AM, Alarcon GS, et al. Derivation and validation of the Systemic Lupus International Collaborating Clinics classification criteria for systemic lupus erythematosus. Arthritis Rheum 64: 2677-2686, 2012.

9. Hirayama K, Kobayashi M, Usui J, et al. Pulmonary involvements of anti-neutrophil cytoplasmic autoantibody-associated renal vasculitis in Japan. Nephrol Dial Transplant 30 (Suppl 1): i83-i93, 
2015.

10. Kostianovsky A, Hauser T, Pagnoux C, et al. Alveolar haemorrhage in ANCA-associated vasculitides: 80 patients' features and prognostic factors. Clin Exp Rheumatol 30: S77-S82, 2012.

11. Hruskova Z, Casian AL, Konopasek $P$, et al. Long-term outcome of severe alveolar haemorrhage in ANCA-associated vasculitis: a retrospective cohort study. Scand J Rheumatol 42: 211-214, 2013.

12. Kemna MJ, Damoiseaux J, Austen J, et al. ANCA as a predictor of relapse: useful in patients with renal involvement but not in patients with nonrenal disease. J Am Soc Nephrol 26: 537-542, 2015.

13. Komatsuda A, Miura I, Ohtani $\mathrm{H}$, et al. Crescentic glomerulonephritis accompanied by myeloperoxidase-antineutrophil cytoplasmic antibodies in a patient having myelodysplastic syndrome with trisomy 7. Am J Kidney Dis 31: 336-340, 1998.
14. Hull DR, McMillan SA, Rea IM, Boyd N, McMullin MF. Antineutrophil cytoplasmic antibodies in myelodysplasia. Ulster Med J 65: 55-57, 1996.

15. Hamidou MA, Derenne S, Audrain MA, Berthelot JM, Boumalassa A, Grolleau JY. Prevalence of rheumatic manifestations and antineutrophil cytoplasmic antibodies in haematological malignancies. A prospective study. Rheumatology 39: 417-420, 2000.

16. Hervier B, Hamidou M, Haroche J, Durant C, Mathian A, Amoura Z. Systemic lupus erythematosus associated with ANCAassociated vasculitis: an overlapping syndrome? Rheumatol Int 32: 3285-3290, 2012.

17. Santos-Ocampo AS, Mandell BF, Fessler BJ. Alveolar hemorrhage in systemic lupus erythematosus: presentation and management. Chest 118: 1083-1090, 2000.

(C) 2015 The Japanese Society of Internal Medicine http://www.naika.or.jp/imonline/index.html 